\title{
EVALUASI KINERJA TATA KELOLA TEKNOLOGI INFORMASI MENGGUNAKAN FRAMEWORK COBIT 5 (STUDI KASUS: PT. ADICIPTA INOVASI TEKNOLOGI)
}

\author{
Antonius $^{1}$, Christ Rudianto², Penidas Fiodinggo Tanaem ${ }^{3}$ \\ Program Studi Sistem Informasi \\ Universitas Kristen Satya Wacana \\ email :1,2,3: 682016004@student.uksw.edu, chris.rudianto@uksw.edu, \\ penidas.fiodinggo@uksw.edu
}

\begin{abstract}
Abstrak
Keberadaan dari teknologi informasi (TI) saat ini sudah menjadi hal yang penting bagi suatu oganisasi untuk meningkatkan efisiensi dan efektifitas kerja. Dengan adanya penggunaan dan penerapan TI, proses bisnis suatu organisasi dapat terbantu contohnya seperti memperoleh informasi yang akurat, tepat waktu, relevan dan membantu pengambilan keputusan. Implementasi TI sendiri membutuhkan investasi yang besar dan resiko yang tinggi, implementasi TI perlu mekanisme tata kelola TI untuk melakukan pengawasan secara menyeluruh agar tujuan bisnis suatu organisasi benar-benar dapat dicapai secara efektif dan efisien dengan adanya penggunaan TI. PT. Adicipta Inovasi Teknologi (AdIns) adalah perusahaan yang didirikan pada tahun 2000 dengan tujuan untuk menjadi penyedia solusi di bidang teknologi informasi untuk mitra perusahaan dan organisasi. Dalam proses bisnis intinya, PT. Adicipta Inovasi Teknologi sangat tergantung dengan teknologi informasi, hampir semua aktivitas menggunakan teknologi informasi seperti komunikasi dengan pihak luar, pencatatan data perusahaan atau organisasi mitra, perhitungan keuangan dan untuk evaluasi pekerjaan. Teknologi informasi yang ada sangat membantu keberlangsungan PT. Adicipta Inovasi Teknologi, tetapi dalam proses bisnis sehariharinya masih ditemui kendala atau permasalahan untuk penggunaan teknologi informasi yang ada, contohnya adalah seperti belum semua pegawai menguasai sistem yang dimiliki oleh perusahaan, database yang jarang diupdate, dan belum adanya Standar Operasional Prosedur (SOP) untuk setiap proses yang ada di perusahaan. Sehingga menimbulkan hasil yang tidak maksimal bagi perusahaan. untuk pengembangan produk, dan standar produk yang digunakan sudah ketinggalan jaman. Berdasarkan hasil penelitian yang dilakukan menggunakan COBIT 5 dapat diambil kesimpulan bahwa kinerja tata kelola teknologi informasi yang ada di PT. Adicipta Inovasi Teknologi pada domain DSS (Deliver, Service, Support) menunjukan PT. Adicipta Inovasi Teknologi telah mengimplementasikan semua sub domain DSS. Namun, sampai sekarang masih belum sepenuhnya melakukan dokumentasi dan proses pengelolaan yang baik. Hal ini terlihat dari hasil penilaian proses capability level dari sub domain yang ada menunjukan 4 dari 6 sub domain masih berada pada level 1, Performed Process.
\end{abstract}

Kata kunci: Evaluasi Kinerja, Tata Kelola Teknologi Informasi, Perusahaan, Framework COBIT 5, Domain Deliver, Support, and Service 


\section{PENDAHULUAN}

Keberadaan dari teknologi informasi (TI) saat ini sudah menjadi hal yang penting bagi suatu oganisasi untuk meningkatkan efisiensi dan efektifitas kerja. Dengan adanya penggunaan dan penerapan TI, proses bisnis suatu organisasi dapat terbantu contohnya seperti memperoleh informasi yang akurat, tepat waktu, relevan dan membantu pengambilan keputusan. Implementasi TI sendiri membutuhkan investasi yang besar dan resiko yang tinggi, implementasi TI perlu mekanisme tata kelola TI untuk melakukan pengawasan secara menyeluruh agar tujuan bisnis suatu organisasi benar-benar dapat dicapai secara efektif dan efisien dengan adanya penggunaan TI.

Menurut Yap (2017), risiko merupakan sesuatu yang tidak pasti dan memiliki dampak yang negatif bagi sebuah tujuan atau keinginan yang ingin diraih. Risiko dapat menjadi tantangan yang besar bagi setiap perusahaan atau organisasi. Dimana perusahaan atau organisasi dituntut untuk dapat melakukan pengelolaan atau manajemen terhadap risiko - risiko yang ada dengan baik. Melalui manajemen risiko yang dikelola dengan baik, maka perusahaan atau organisasi mampu melindungi atau menjaga nilai (protecting value) dan menciptakan nilai tambah (creating added value) bagi perusahaan atau organisasi.

PT. Adicipta Inovasi Teknologi (AdIns) adalah perusahaan yang didirikan pada tahun 2000 dengan tujuan untuk menjadi penyedia solusi di bidang teknologi informasi untuk mitra perusahaan dan organisasi. Dalam proses bisnis intinya, PT. Adicipta Inovasi Teknologi sangat tergantung dengan teknologi informasi, hampir semua aktivitas menggunakan teknologi informasi seperti komunikasi dengan pihak luar, pencatatan data perusahaan atau organisasi mitra, perhitungan keuangan dan untuk evaluasi pekerjaan. Teknologi informasi yang ada sangat membantu keberlangsungan PT. Adicipta Inovasi Teknologi, tetapi dalam proses bisnis sehariharinya masih ditemui kendala atau permasalahan untuk penggunaan teknologi informasi yang ada, contohnya adalah seperti belum semua pegawai menguasai sistem yang dimiliki oleh perusahaan, database yang jarang diupdate, dan belum adanya Standar Operasional Prosedur (SOP) untuk setiap proses yang ada di perusahaan. Sehingga menimbulkan hasil yang tidak maksimal bagi perusahaan. untuk pengembangan produk, dan standar produk yang digunakan sudah ketinggalan jaman.

Dalam memastikan tata kelola teknologi informasi sudah berjalan dengan baik, dapat dilakukan audit dan analisis terhadap tata kelola teknologi informasi dengan menggunakan beberapa framework sebagai acuan standar, seperti COBIT, COSO, ITIL, ISO dan lain-lain. Dalam penelitian ini, penulis menggunakan COBIT 5 (Control Objectives for Information and related Technology) sebagai model framework. COBIT 5 dipilih karena merupakan kerangka kerja yang komprehensif dan dapat membantu perusahaan mencapai tujuan melalui tata kelola dan manajemen teknologi informasi yang efektif. COBIT 5 menyediakan kerangka kerja IT govenance dan control objectives yang rinci bagi manajemen, pemilik proses bisnis, pemakai dan auditor, hal ini dikarenakan COBIT 5 mengelola teknologi informasi secara holistic sehingga nilai yang diberikan oleh teknologi informasi dapat tercapai secara optimal dengan memperhatikan segala aspek tata kelola teknologi informasi mulai dari sisi people, skills, competencies, services, infrastructure dan applications yang merupakan bagian dari enabler tata kelola teknologi informasi (Wijaya, 2017). Dalam penelitian ini, COBIT 5 digunakan khususnya adalah bagian domain Deliver, Service and Support (DSS) dimana merupakan domain untuk menilai tentang pemberian layanan teknologi informasi serta dukungannya termasuk pengelolaan masalah agar keberlanjutan layanan tetap berjalan. Dalam penelitian ini digunakan domain DSS dalam COBIT 5 untuk penelitian ini dikarenakan masalah yang ada di PT. Adicipta Inovasi Teknologi adalah kurang maksimalnya pemberian layanan teknologi informasi serta dukungannyayakni tidak terup-to-date nya pengembangan produk yang diinginkan oleh pelanggan. Responden dalam penelitian ini, mengacu pada RACI chart yang ada. Dengan dilakukannya evaluasi kinerja 
terhadap tata kelola teknologi informasi, diharapkan PT. Adicipta Inovasi Teknologi dapat mengetahui kinerja dari tata kelola teknologi informasi di dalam perusahaan dan menjadikan hasil evaluasi sebagai solusi dan rekomendasi untuk mendukung keberlangsungan bisnis dari PT. Adicipta Inovasi Teknologi mencapai tujuan bisnisnya. Berdasarkan penelitian yang pernah dilakukan sebelumnya oleh Achyar Al-Rasyid mengenai audit sistem informasi menggunakan COBIT 5 yang berfokus pada domain Deliver, Service, and Support (DSS) bertujuan untuk mengevaluasi, menilai kapabilitas, dan menyusun rekomendasi terhadap tata kelola TI aplikasi Sistem Informasi Manajemen Bina Lingkungan (SIM-BL) pada unit Community Development Center (CDC) dimana PT Telkom belum pernah melakukan evaluasi tata kelola TI untuk unit tersebut. Kesimpulan yang didapatkan dari penelitian tersebut adalah Capability Level yang ada di SIM-BL unit CDC berada pada level 4, yaitu Predictable Process dan level yang diinginkan adalah level 5, Optimizing Process, sehingga berdasarkan analisis gap secara garis besar untuk mencapai tujuan level yang diinginkan adalah dengan cara memaksimalkan tata kelola TI yang sudah berjalan dan melakukan inovasi dalam aktivitasnya (Achyar, 2015).

Penelitian selanjutnya dilakukan oleh Rio Kurnia Candra, Imelda Atastina, dan Yanuar Firdaus mengenai audit teknologi informasi menggunakan framework COBIT 5 pada domain DSS dimana studi kasusnya adalah sistem informasi iGracias (Integrated Academic Information System) di Universitas Telkom. Penelitian ini bertujuan untuk mengevaluasi dan mengukur apakah teknologi yang diimplementasikan untuk iGracias sudah sesuai dengan yang diharapkan dan mampu memudahkan proses bisnis dari Universitas Telkom. Hasil penelitian tersebut menunjukan 1 proses berada pada level 4, yaitu DSS02 dan 5 proses lainnya DSS01, DSS03, DSS04, DSS05, DSS06 berada pada level 3 (Yanuar, 2015).

\section{RUANG LINGKUP}

Ruang lingkup dari penelitian yang dilakukan yaitu cakupan permasalahannya pada pelaksanaan evaluasi kinerja tata kelola TI di PT. Adicipta Inovasi Teknologi selama ini dilakukan hanya jika diperlukan saja. Oleh karena itu, dibutuhkan audit dan analisis tata kelola TI secara menyeluruh dimana dalam evaluasi kinerja ini hanya fokus terhadap domain DSS yang ada dalam framework COBIT 5 sebagai acuan. Batasan penelitian ini berfokus pada TI yang ada pada PT. Adicipta Inovasi Teknologi. Penelitian ini akan berfokus kepada proses evaluasi kinerja terhadap tata kelola TI pada PT. Adicipta Inovasi Teknologi secara menyeluruh yakni mulai dari peraturan dan prosedur, perangkat yang digunakan, serta sistem yang ada. Selama ini, penggunaan TI yang ada dalam perusahaan masih belum maksimal, masih mengalami masalah dan belum pernah dilakukan evaluasi kinerja terhadap tata kelola TI yang ada pada perusahaan ini. Hal lain yang berbeda dari penelitian sebelumnya adalah penulis juga melakukan observasi yang mendalam selama 6 bulan mengamati dan menggunakan TI di PT. Adicipta Inovasi Teknologi secara langsung. Hasil dari penelitian ini adalah berupa temuan-temuan yang akan menjadi rekomendasi dan saran sehingga tata kelola TI yang ada di PT. Adicipta Inovasi Teknologi dapat maksimal demi mendukung mencapai tujuan bisnis perusahaan secara efektif. 


\section{METODOLOGI PENELITAN}

Tata kelola teknologi informasi adalah suatu cabang tata kelola perusahaan yang berfokus pada manajemen teknologi informasi dan resikonya. Tata kelola TI menekankan agar teknologi informasi perusahaan selaras dengan tujuan bisnis perusahaan. Tata kelola teknologi informasi juga menguraikan bagaimana organisasi mengatur dan mengurus sumber daya TI dengan mempertimbangkan pengawasan serta pengendalian sumber daya TI yang diterapkan oleh perusahaan (Achyar, 2015).

Menurut ISACA (2014), framework COBIT 5 adalah salah satu kerangka kerja bagi tata kelola dan manajemen teknologi informasi perusahaan atau organisasi. Framework COBIT 5 merupakan framework yang menggabungkan tata kelola TI perusahaan dan cara manajemen serta mempunyai prinsip - prinsip, praktek, alat - alat analisis, dan model yang diterima secara global untuk membantu meningkatkan kinerja tata kelola TI di perusahaan atau organisasi. Implementasi framework COBIT 5 dalam suatu perusahaan atau organisasi mempunyai beberapa kegunaan, antara lain adalah menjaga kualitas informasi guna mendukung keputusan bisnis, menghasilkan nilai bisnis dari investasi pemanfaatan TI guna mencapai tujuan strategis dan merealisasikan manfaat bisnis perusahaan atau organisasi melalui penerapan TI yang efektif dan inovatif. Melalui implementasi TI, perusahaan atau organisasi juga dapat memperoleh keunggulan operasional yang baik dan efisien. Perusahaan atau organisasi juga dapat menjagi risiko implementasi TI pada tingkat yang dapat ditoleransi serta dapat mengoptimalkan biaya yang dikeluarkan untuk penggunaan layanan TI (ISACA, 2015). COBIT 5 menyediakan sebuah kerangka yang komprehensif untuk membantu perusahaan mencapai tujuannya dalam tata kelola dan manajemen TI. Framework COBIT 5 memungkinkan TI untuk diatur dan dikelola secara holistik, dari pengambilan keputusan oleh bidang fungsional TI yang bertanggungjawab atas keputusan tersebut agar memenuhi kebutuhan pemangku kepentingan sampai ke pemisahan tata kelola TI dari manajemennya.

Dalam COBIT 5 hal tersebut digambarkan dalam prinsip-prinsip yang dimiliki oleh COBIT 5, Gambar 1 merupakan gambaran prinsip-prinsip tersebut (ISACA, 2014):

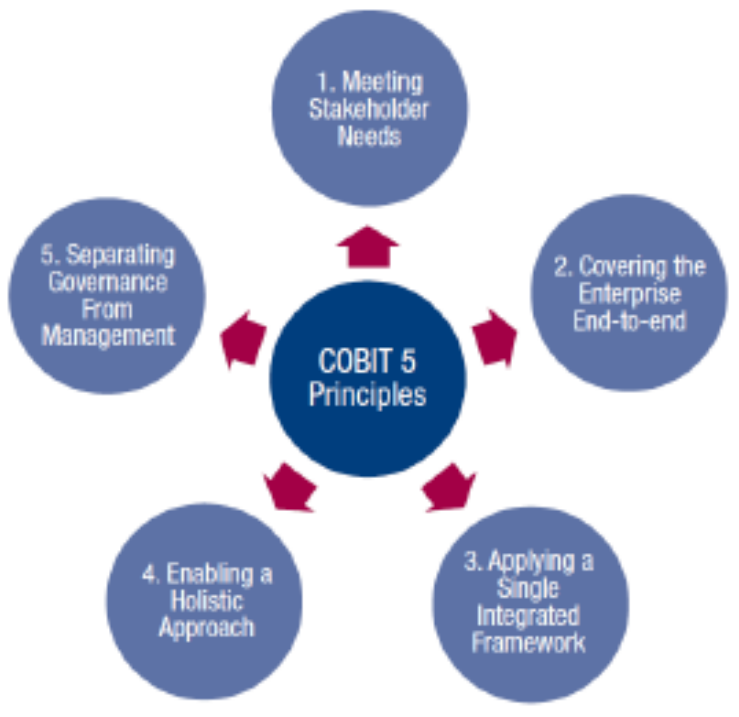

Gambar 1. COBIT 5 Principles

(Sumber: ISACA, 2014) 
Berikut penjelasan mengenai 5 prinsip COBIT 5 di atas:

a) Meeting Stakeholder Needs: COBIT 5 menyediakan semua proses yang dibutuhkan untuk membantu perusahaan memenuhi kebutuhan pemangku kepentingan dalam perusahaan lewat penggunaan TI.

b) Covering the Enterprise End-to-end: COBIT 5 mengintegrasikan tata kelola TI ke tata kelola perusahaan.

c) Applying a Single Framework: COBIT 5 dikenal sebagai framework tata kelola TI yang lengkap dan standar yang mencakup banyak framework tata kelola yang ada.

d) Enabling a Holistic Approach: COBIT 5 mempunyai beberapa enablers untuk membantu mengimplementasikan tata kelola yang mudah dipahami dan sistem manajemen TI perusahaan.

e) Separating Governance from Management: COBIT 5 jelas sekali membedakan antara tata kelola dan manajemen. 2 hal tersebut mengarah pada aktivitas yang berbeda, membutuhkan struktur organisasi yang beda dan memiliki fungsi yang berbeda pula.

Pengumpulan

Dalam COBIT 5 penilaian kematangan tata kelola TI menggunakan Capability Model. Jumlah level penilaian ini terbagi dalam enam level, berikut penjelasan level dari Process Capability (ISACA, 2014):

a) Level 0 Incomplete Process

Proses tidak dilaksanakan atau gagal untuk mencapai tujuan prosesnya. Pada level ini, ada sedikit atau tidak ada sama sekali bukti dari setiap pencapaian tujuan proses.

b) Level 1 Performed Process

Proses diimplementasikan untuk mencapai tujuan bisnisnya.

c) Level 2 Managed Process

Proses yang diimplementasikan dikelola (planned, monitored and adjusted) dan hasilnya ditetapkan dan dikontro.

d) Level 3 Established Process

Proses didokumentasikan dan dikomunikasikan (untuk efisiensi organisasi).

e) Level 4 Predictable Process

Proses dimonitor, diukur dan diprediksi untuk mencapai hasil.

f) Level 5 Optimizing Process

Proses diprediksikan kemudian ditingkatkan untuk memenuhi tujuan bisnis yang relevan dan nantinya akan relevan dengan tujuan bisnis yang akan dating.

Selain itu, COBIT 5 juga memiliki 5 Domain yang terbagi atas 37 proses TI dimana nantinya akan dianalisa sesuai dengan keadaan perusahaan, 37 proses yang ada dapat dilihat pada Gambar 2 berikut: 


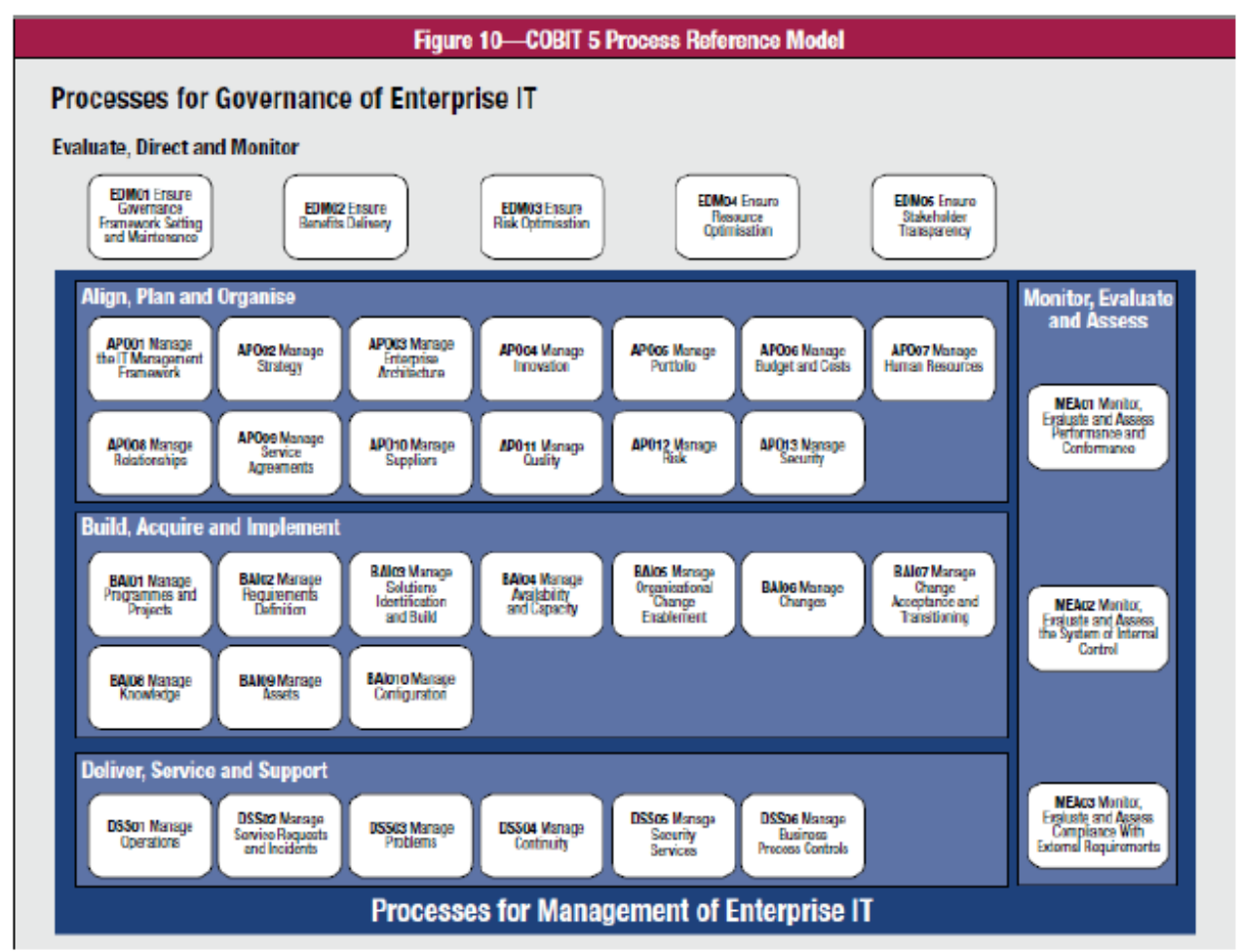

Gambar 2. COBIT 5 Process Reference Model (Sumber: ISACA 2014)

Berikut adalah penjelasan secara umum tentang 5 domain COBIT (ISACA, 2014):

a) Evaluate, Direct and Monitor (EDM), merupakan domain yang berbicara tentang penilaian dan evaluasi, pengarahan dan pengawasan, domain EDM memiliki 5 sub domain. Domain EDM ini berasal dari area governance of enterprise IT.

b) Align, Plan and Organize (APO), merupakan domain yang berbicara tentang penyelarasan, perencanaan dan pengolahan TI, domain APO memiliki 13 sub domain. Domain APO berasal dari management of enterprise IT.

c) Build, Acquire and Implement (BAI), merupakan domain pembangunan dan pengimplementasian TI, domain BAI memiliki 10 sub domain. Domain BAI berasal dari area management of enterprise IT.

d) Deliver, Service and Support (DSS), merupakan domain yang berbicara tentang pengiriman pemberian layanan dan support TI untuk perusahaan atau organisasi, domain ini memiliki 6 sub domain. Domain DSS berasal dari area management of enterprise IT.

e) Monitor, Evaluate and Assess (MEA), merupakan domain pengawasan, evaluasi dan proses pencobaan TI di perusahaan atau organisasi, domain ini memiliki 3 sub domain. Domain MEA berasal dari area management of enterprise IT.

Untuk mengetahui proses mana saja yang akan dianalisa sesuai dengan keadaan perusahaan, dalam COBIT 5 kita perlu melakukan pemetaan terlebih dahulu enterprise goals dan IT-related goals yang ada dalam perusahaan. Pemetaan dapat dilakukan setelah kita mengetahui tujuan bisnis perusahaan dan memetakannya terlebih dahulu dalam tujuan bisnis COBIT 5. 
Domain Deliver, Service and Support (DSS) merupakan salah satu domain yang ada dalam COBIT 5. Fokus dari domain DSS adalah pada aspek pengiriman layanan teknologi informasi, proses dan dukungannya yang memungkinkan untuk mencapai operasional TI yang efektif dan efisien.

Domain DSS terdiri dari 6 control objective, yaitu sebagai berikut:

a) DSS01 - Mengelola Operasi.

b) DSS02 - Mengelola Permintaan Layanan dan Insiden.

c) DSS03 - Mengelola Masalah.

d) DSS04 - Mengelola Keberlanjutan.

e) DSS05 - Mengelola Keamanan Layanan.

f) DSS06 - Mengelola Kontrol Proses Bisnis.

RACI Chart atau Diagram RACI adalah bagian dari Responsibility Assignment Matrix (RAM), yaitu bentuk pemetaan antara sumberdaya dengan aktivitas dalam setiap prosedur. $R A C I$ merupakan singkatan dari Responsibility, Accountable, Consulted, dan Informed. Dalam COBIT 5, diagram RACI digunakan untuk menentukan responden dalam organisasi yang akan diwawancarai secara tepat. Diagram RACI sendiri memiliki penjabaran untuk setiap bagiannya.

Berikut merupakan penjelasan dari tiap bagian (Yanuar, 2015):

a) $\quad \mathrm{R}$ (Responsible), berarti bahwa bagian tersebut merupakan pihak pelaksana yang harus bertanggung jawab melaksanakan dan menyelesaikan aktivitas yang menjadi tanggung jawabnya.

b) A (Accountable), berarti bahwa bagian tersebut merupakan pihak yang harus mengarahkan jalannya pelaksanaan aktivitas.

c) $\mathrm{C}$ (Consulted), berarti bahwa bagian tersebut merupakan pihak yang akan menjadi tempat konsultasi selama pelaksanaan aktivitas.

d) I (Informed), berarti bahwa bagian tersebut merupakan pihak yang diberikan informasi mengenai pelaksanaan aktivitas.

Dalam penelitian di PT. Adicipta Inovasi Teknologi, metode yang digunakan adalah mix method, yang berarti penelitian ini dilakukan dengan cara kombinasi metode penelitian kualitatif untuk pengumpulan data melalui observasi dan wawancara sedangkan metode kuantitatif untuk pengumpulan data melalui kuesioner. Berikut langkah-langkah yang dilakukan dalam penelitian ini:

Tahapan pertama dalam penelitian ini adalah studi pustaka dimana penulis mengumpulkan informasi dan mempersiapkan tool dalam penelitian yakni COBIT 5. Tahapan selanjutnya adalah studi awal terhadap tempat studi kasus, mencari informasi mengenai PT. Adicipta Inovasi Teknologi. Dari beberapa narasumber seperti, Human Capital Head, Human Resources and General Affair, dan Head IT Support di PT. Adicipta Inovasi Teknologi, penulis melakukan wawancara dan mengumpulkan data-data yang diperlukan, seperti profil PT. Adicipta Inovasi Teknologi hingga keadaan tata kelola teknologi yang dimiliki PT. Adicipta Inovasi Teknologi. 
Setelah dilakukannya studi awal terhadap tempat studi kasus, tahap selanjutnya adalah pemetaan COBIT 5 dimana didalam tahapan ini dilakukan penyelarasan antara tujuan bisnis perusahaan dan tujuan TI PT. Adicipta Inovasi Teknologi. Proses penyelarasan tersebut dilakukan dengan menggunakan tool IT balanced scorecard (IT BSC) yang merupakan alat pemetaan proses bisnis internal organisasi dari berbagai perspektif; perspektif keuangan, perspektif pelanggan, perspektif proses bisnis internal, perspektif pembelajaran dan pengembangan. Proses penyelarasan tujuan bisnis dan tujuan TI perlu dilakukan sehingga organisasi dapat mencapai tujuan dengan dukungan TI yang dimilikinya.

Selanjutnya dilakukan pengumpulan data melalui wawancara dan kuesioner terhadap responden yang telah ditentukan di dalam $R A C I$ chart untuk melengkapi data yang telah didapat di dalam tahapan studi awal. Pengumpulan data dilakukan dengan 3 metode, yaitu wawancara, kuesioner dan observasi. Penulis melakukan wawancara terhadap responden yang telah ditetapkan melalui RACI chart kemudian melakukan penilaian melalui kuesioner yang ada dan melakukan observasi terhadap tempat studi kasus secara langsung, melihat bagaimana keadaan tata kelola TI yang ada di PT. Adicipta Inovasi Teknologi.

Setelah melakukan pengamatan untuk mendapatkan data yang cukup, tahapan yang dilakukan adalah analisis data. Peneliti menganalisa data yang didapat dari hasil wawancara dengan narasumber di PT. Adicipta Inovasi Teknologi, yaitu Human Capital Head, Human Resources and General Affair, dan Head IT Support, selain itu juga melakukan analisa akan dilakukan proses penilaian kapabilitas menggunakan form penilaian yang akan menghasilkan gambaran keadaan tata kelola teknologi yang ada di perusahaan. Ada juga proses analisa kesenjangan yang nantinya akan memperlihatkan bagaimana keadaan dan target tujuan yang seharusnya didapatkan agar keadaan tata kelola teknologi informasi dapat optimal. Setelah beberapa proses penilaian dan analisa dilakukan, peneliti akan memberikan rekomendasirekomendasi untuk memperbaiki keadaan tata kelola teknologi informasi perusahaan saat ini yang dirasa belum optimal.

Tahapan terakhir dalam penelitian ini adalah membuat kesimpulan dari penelitian ini, kesimpulan dibuat dari rangkuman hasil analisa yang telah dilakukan dan rekomendasi untuk perbaikan tata kelola teknologi informasi PT. Adicipta Inovasi Teknologi.

\section{HASIL DAN PEMBAHASAN}

Pemetaan RACI chart

\begin{tabular}{lll}
\hline \multicolumn{1}{c}{ Peran RACI (RACI Role) } & & Jabatan \\
\hline Responsible & - & Head IT Support \\
Accountable & - & Head IT Support \\
Consulted & - & Human Resources and General Affair \\
Informed & - & Human Capital Head \\
\hline
\end{tabular}

Tahapan pertama adalah melakukan analisis tujuan strategis di PT. Adicipta Inovasi Teknologi. Analisis dapat dilakukan dengan menggunakan Balanced Scorecard (BSC) yang memiliki 4 perspektif yaitu financial perspective, customer perspective, internal process perspective, dan learning and growth perspective. 
Berikut adalah hasil analisis tujuan strategis PT. Adicipta Inovasi Teknologi:

\begin{tabular}{lll}
\hline \multicolumn{1}{c}{ Perspektif } & \multicolumn{1}{c}{ Tujuan Strategis } \\
\hline Finansial & - & Mengontrol penggunaan dana dalam keberlangsungan proses bisnis \\
& perusahaan. \\
Pelanggan & - & Menghasilkan solusi teknologi informasi bagi perusahaan atau organisasi \\
& secara berkelanjutan. \\
Internal & - & Mengembangkan aplikasi TI untuk mendukung proses bisnis perusahaan. \\
Pembelajaran dan & - & Mengadakan pelatihan bagi para pegawai untuk meningkatkan \\
Pengembangan & & kemampuan TI pegawai yang diadakan setiap bulan. \\
& - & Merencanakan pengadaan pelatihan workshop untuk para pegawai untuk \\
& melatih kemampuan pegawai di bidangnya, khususnya bidang TI. \\
\hline
\end{tabular}

Setelah melakukan analisis tujuan strategis, tahap selanjutnya dilakukan analisis dan penyelarasan tujuan strategis PT. Adicipta Inovasi Teknologi dengan Enterprise Goals dalam COBIT 5. Untuk proses analisisnya akan dilihat keterkaitan antara tujuan strategis PT. Adicipta Inovasi Teknologi dengan Enterprise Goals COBIT 5. Berikut adalah Enterprise Goals yang terkait dengan Enterprise Goals COBIT 5 adalah sebagai beriku:

Enterprise Goals yang terpilih

\begin{tabular}{|c|c|c|c|}
\hline No & $\begin{array}{l}\text { Kode Enterprise } \\
\text { Goals COBIT } 5\end{array}$ & Deskripsi & $\begin{array}{l}\text { Keterkaitan dengan } \\
\text { Enterprise Goals PT. } \\
\text { Adicipta Inovasi Teknologi }\end{array}$ \\
\hline 1 & EG1 & $\begin{array}{l}\text { Stakeholder value of business } \\
\text { investment }\end{array}$ & Tidak terkait \\
\hline 2 & EG2 & $\begin{array}{l}\text { Portofolio of competitive products } \\
\text { and services }\end{array}$ & Tidak terkait \\
\hline 3 & EG3 & $\begin{array}{l}\text { Managed business risks } \\
\text { (Safeguarding assets) }\end{array}$ & Tidak terkait \\
\hline 4 & EG4 & $\begin{array}{l}\text { Compliance with external laws and } \\
\text { regulations }\end{array}$ & Tidak terkait \\
\hline 5 & EG5 & Financial Transparency & Ada keterkaitan \\
\hline 6 & EG6 & Customer oriented service culture & Ada keterkaitan \\
\hline 7 & EG7 & $\begin{array}{l}\text { Business service continuity and } \\
\text { availability }\end{array}$ & Ada keterkaitan \\
\hline 8 & EG8 & $\begin{array}{l}\text { Agile responses to a changing } \\
\text { business environment }\end{array}$ & Tidak terkait \\
\hline 9 & EG9 & $\begin{array}{l}\text { Information based strategic decision } \\
\text { making }\end{array}$ & Ada keterkaitan \\
\hline 10 & EG10 & Optimisation of service delivery costs & Ada keterkaitan \\
\hline 11 & EG11 & $\begin{array}{l}\text { Optimisation of business process } \\
\text { functionality }\end{array}$ & Tidak terkait \\
\hline 12 & EG12 & $\begin{array}{l}\text { Optimisation of business process } \\
\text { costs }\end{array}$ & Tidak terkait \\
\hline
\end{tabular}




\begin{tabular}{llll}
\hline 13 & EG13 & $\begin{array}{l}\text { Managed business change } \\
\text { programmes }\end{array}$ & Tidak terkait \\
14 & EG14 & $\begin{array}{l}\text { Operational and staff productivity } \\
\text { Compliance with internal policies }\end{array}$ & Ada keterkaitan \\
15 & EG15 & Tidak terkait \\
16 & EG16 & $\begin{array}{l}\text { Skilled and motivated people } \\
\text { Product and business innovation } \\
\text { culture }\end{array}$ & Ada keterkaitan \\
\hline
\end{tabular}

Setelah dilakukan pemetaan Enterprise Goals dengan IT-related Goals yang ada, maka akan terlihat IT-related Goals mana saja yang akan digunakan untuk pemilihan proses COBIT 5 yang digunakan. Berikut adalah tabel yang menunjukan Enterprise Goals dan IT-related Goals yang terpilih:

\begin{tabular}{llll}
\hline No & $\begin{array}{l}\text { Kode Enterprise } \\
\text { Goals COBIT 5 }\end{array}$ & $\begin{array}{l}\text { Keterkaitan dengan Enterprise Goals } \\
\text { PT. Adicipta Inovasi Teknologi }\end{array}$ & IT-related Goals COBIT 5 \\
\hline 1 & EG5 & Ada keterkaitan & 6 \\
2 & EG6 & Ada keterkaitan & 1,7 \\
3 & EG7 & Ada keterkaitan & $4,10,14$ \\
4 & EG9 & Ada keterkaitan & 1,14 \\
5 & EG10 & Ada keterkaitan & $4,6,11$ \\
6 & EG14 & Ada keterkaitan & 8,16 \\
7 & EG16 & Ada keterkaitan & 16 \\
\hline
\end{tabular}

Setelah dilakukan pemetaan IT-related Goals ke COBIT 5 process, maka akan terlihat proses mana saja yang terpilih, berikut adalah tabel IT-related Goals dan COBIT 5 process yang terpilih:

\begin{tabular}{|c|c|c|}
\hline No & $\begin{array}{l}\text { IT-related } \\
\text { Goals }\end{array}$ & COBIT 5 process \\
\hline 1 & IT-G1 & $\begin{array}{l}\text { EDM01, EDM02, APO01, APO02, APO03, APO05, APO07, APO08, } \\
\text { BAI01, BAI02 }\end{array}$ \\
\hline 2 & IT-G4 & $\begin{array}{l}\text { EDM03, APO10, APO12, APO13, BAI01, BAI06, DSS01, DSS01, } \\
\text { DSS03, DSS04, DSS05, DSS06, MEA01, MEA02, MEA03 }\end{array}$ \\
\hline 3 & IT-G6 & EDM02, EDM03, EDM05, APO06, APO12, APO13, BAI09 \\
\hline 4 & IT-G7 & $\begin{array}{l}\text { EDM01, EDM02, EDM05, APO02, APO08, APO09, APO10, APO11, } \\
\text { BAI02, BAI03, BAI04, BAI06, DSS01, DSS02, DSS03, DSS04, } \\
\text { DSS06, MEA01 }\end{array}$ \\
\hline 5 & IT-G8 & APO04, BAI05, BAI07 \\
\hline 6 & IT-G10 & EDM03, APO12, APO13, BAI06, DSS05 \\
\hline 7 & IT-G11 & $\begin{array}{l}\text { EDM04, APO01, APO03, APO04, APO07, BAI04, BAI09, BAI10, } \\
\text { DSS01, DSS03, MEA01 }\end{array}$ \\
\hline 8 & IT-G14 & APO09, APO13, BAI04, BAI10, DSS03, DSS04 \\
\hline 9 & IT-G16 & EDM04, APO01, APO07 \\
\hline
\end{tabular}


Setelah mengetahui IT-related Goals dan sub domain atau proses mana saja yang terpilih maka dipilihlah proses sub domain DSS yang menjadi fokus dari penelitian ini. Berikut adalah tabel sub domain DSS yang terpilih dalam fokus penelitian ini:

\begin{tabular}{ll}
\hline \multicolumn{1}{c}{ Kode Proses } & \multicolumn{1}{c}{ Practice } \\
\hline DSS01 & - Mengelola operasi perusahaan \\
DSS02 & - Mengelola permintaan layanan dan insiden \\
DSS03 & - Mengelola masalah \\
DSS04 & - Mengelola keberlanjutan proses bisnis \\
DSS05 & - Mengelola keamanan layanan pelanggan \\
DSS06 & - Mengelola kontrol proses bisnis perusahaan \\
\hline
\end{tabular}

Berikut adalah hasil temuan dari sub domain yang ada melalui pengumpulan data wawancara, kuesioner dan pengamatan langsung yang dilakukan di tempat:

Kode Proses Practice Temuan

\begin{tabular}{|c|c|}
\hline asi & $\begin{array}{l}\text { - PT. Adicipta Inovasi Teknologi belum memiliki SOP untuk } \\
\text { penggunaan komputer, perawatan komputer dan sistem. } \\
\text { - } \\
\text { PT. Adicipta Inovasi Teknologi tidak memiliki jadwal } \\
\text { monitoring berkala untuk sistem. } \\
\text { - } \\
\text { PT. Adicipta Inovasi Teknologi tidak memiliki pelatihan TI } \\
\text { khusus untuk karyawannya. } \\
\text { - } \\
\text { PT. Adicipta Inovasi Teknologikekurangan tenaga kerja untuk } \\
\text { bagian TI nya. }\end{array}$ \\
\hline $\begin{array}{l}\text { DSS02 Mengelola } \\
\text { permintaan layanan dan } \\
\text { insiden }\end{array}$ & - Sudah memiliki SOP yang jelas untuk permintaan layanan. \\
\hline DSS03 Mengelola & - Tidak ada dokumentasi untuk permasalahan yang ada. \\
\hline masalah & $\begin{array}{l}\text { - Ada monitoring untuk memastikan perangkat yang mengalami } \\
\text { masalah sudah teratasi. }\end{array}$ \\
\hline DSS04-Mengelola & - Tidak memiliki SOP untuk perawatan sistem dan database. \\
\hline keberlanjutan & - Tidak tahu kapan dilakukannya perawatan. \\
\hline $\begin{array}{l}\text { DSS05-Mengelola } \\
\text { keamanan layanan }\end{array}$ & $\begin{array}{l}\text { - Tidak ada SOP perawatan komputer, penggunaan komputer dan } \\
\text { perawatan sistem sehingga menyebabkan tidak jelasnya } \\
\text { keamanan layanan yang ada. } \\
\text { - Semua komputer telah memiliki antivirus dan firewall. }\end{array}$ \\
\hline $\begin{array}{l}\text { DSS06-Mengelola kontrol } \\
\text { proses bisnis }\end{array}$ & $\begin{array}{l}\text { - Ada kontrol terhadap proses bisnis yang ada, contohnya melalui } \\
\text { absensi karyawan. } \\
\text { - Belum ada SOP untuk mengontrol proses bisnis yang ada. }\end{array}$ \\
\hline
\end{tabular}


Proses ini didapatkan dari wawancara dengan beberapa responden RACI chart. Dari pengumpulan temuan yang ada, akan didapatkan nilai proses capability level dari proses COBIT yang terpilih. Berikut adalah hasil penilaian dari temuan yang didapat:

\begin{tabular}{|c|c|c|c|c|c|c|c|}
\hline $\begin{array}{l}\text { Process } \\
\text { ID } \\
\end{array}$ & Process Name & Level 0 & Level 1 & Level 2 & Level 3 & Level 4 & Level 5 \\
\hline \multicolumn{8}{|c|}{$\begin{array}{l}\text { Deliver, Service and } \\
\text { Support (DSS) }\end{array}$} \\
\hline DSS01 & $\begin{array}{l}\text { Manage } \\
\text { Operations }\end{array}$ & & * & & & & \\
\hline DSS02 & $\begin{array}{l}\text { Manage Service } \\
\text { Requests and } \\
\text { Incidents }\end{array}$ & & & & * & & \\
\hline DSS03 & $\begin{array}{l}\text { Manage } \\
\text { Problems }\end{array}$ & & & * & & & \\
\hline DSS04 & $\begin{array}{l}\text { Manage } \\
\text { Continuity }\end{array}$ & & $*$ & & & & \\
\hline DSS05 & $\begin{array}{l}\text { Manage Security } \\
\text { Services }\end{array}$ & & $*$ & & & & \\
\hline DSS06 & $\begin{array}{l}\text { Manage Business } \\
\text { Process Controls }\end{array}$ & & $*$ & & & & \\
\hline
\end{tabular}

Berdasarkan hasil analisis perhitungan tingkat kematangan kinerja tata kelola teknologi informasi yang ada di PT. Adicipta Inovasi Teknologi dapat diketahui bahwa setiap sub domain telah diimplementasikan untuk mencapai tujuan bisnis PT. Adicipta Inovasi Teknologi. Berikut bahasan kondisi lebih rinci mengenai sub domain DSS yang ada:

a. DSS01 (Manage Operations)

Pada proses ini, operasional TI yang ada pada PT. Adicipta Inovasi Teknologi sudah berjalan dengan baik, semua kegiatan dalam penggunaan TI sudah berjalan sesuai koordinasi bagian TI dengan bagian lain akan tetapi, hasil dari proses capability level dari sub mengelola operasi di PT. Adicipta Inovasi Teknologi hanya berada di level 1 yaitu Performed Process. Hal ini dikarenakan operasional TI PT. Adicipta Inovasi Teknologi masih belum memiliki Standart Operasional Prosedur (SOP) yang ditentukan oleh bagian TI, operasional TI hanya diimplementasikan tanpa ada aturan yang jelas.

b. DSS02 (Manage Service Requests and Incidents)

Dalam pemintaan layanan TI yang ada, bagian TI PT. Adicipta Inovasi Teknologi telah memiliki SOP yang jelas untuk permintaan layanan, ada proses dokumentasi dan komunikasi oleh pihak TI dimana pemintaan atas layanan yang diajukan harus melewati persetujuan pihak manajemen dan atasan. Oleh sebab itu hasil dari proses capability level dari sub mengelola bantuan layanan dan insiden di PT. Adicipta Inovasi Teknologi berada pada level 
3 yaitu Established Process, karena telah didokumentasikan dan dikoordinasikan dengan baik.

c. DSS03 (Manage Problems)

Pada proses ini pihak TI PT. Adicipta Inovasi Teknologi telah mengelola dengan baik masalah TI yang ada di perusahaan tersebut, mereka melakukan identifikasi dan mengatasi langsung masalah yang ada, tetapi tidak ada dokumentasi yang dilakukan. Hasil dari proses capability level dari sub mengelola masalah di PT. Adicipta Inovasi Teknologi sendiri berada di level 2 yaitu Managed Process.

d. DSS04 (Managed Continuity)

Pada proses ini yang dilakukan adalah membangun dan memelihara rencana yang memungkinkan bisnis dan TI menanggapi masalah dan gangguan sehingga proses bisnis penting tetap berjalan dan menjaga ketersediaan informasi untuk organisasi. Hasil dari proses capability level dari sub mengelola keberlangsungan di PT. Adicipta Inovasi Teknologi adalah level 1 yaitu Performed Process. Pihak TI PT. Adicipta Inovasi Teknologi masih belum memilki SOP yang jelas untuk mengatur operasional TI perusahaan, hal tersebut mengakibatkan tidak jelasnya kapan pihak TI melakukan maintenance perangkat yang ada dan kapan dilakukannya back-up data untuk menjaga keberlangsungan proses bisnis PT. Adicipta Inovasi Teknologi jika sewaktu-waktu mengalami gangguan.

e. Analisis Dampak (Impact)

Proses yang dilakukan dalam sub domain ini adalah melindungi informasi organisasi untuk mempertahankan tingkat keamanan informasi sesuai dengan kebijakan keamanan. Hasil dari proses capability level dari sub mengelola keamanan sistem di PT. Adicipta Inovasi Teknologi adalah level 1, yaitu Performed Process. Komputer yang ada di PT. Adicipta Inovasi Teknologi, sudah menggunakan antivirus dan firewall untuk keamanannya.

\section{f. $\quad$ DSS06 (Manage Business Process Controls)}

Pada proses ini yang seharusnya dilakukan oleh organisasi adalah mendefinisikan dan mempertahankan kontrol proses bisnis yang tepat untuk memastikan aktivitas yang dilakukan telah sesuai dengan tujuan yang diharapkan. Hasil dari proses capability level dari sub mengelola kontrol proses bisnis di PT. Adicipta Inovasi Teknologi adalah level 1 dimana PT. Adicipta Inovasi Teknologi telah mengupayakan kontrol bisnisnya, contohnya melalui absensi karyawan.

Analisis kesenjangan (Gap Analysis) dilakukan untuk mengetahui sejauh mana kondisi sekarang dengan kondisi yang diharapkan. Kondisi saat ini diketahui dari hasil analisa penilaian menggunakan COBIT 5, sedangkan kondisi yang diharapkan didapat berdasarkan target yang ditetapkan oleh PT. Adicipta Inovasi Teknologi dengan mempertimbangkan sumber daya yang ada. Berikut kesenjangan yang terlihat dari gambar. 


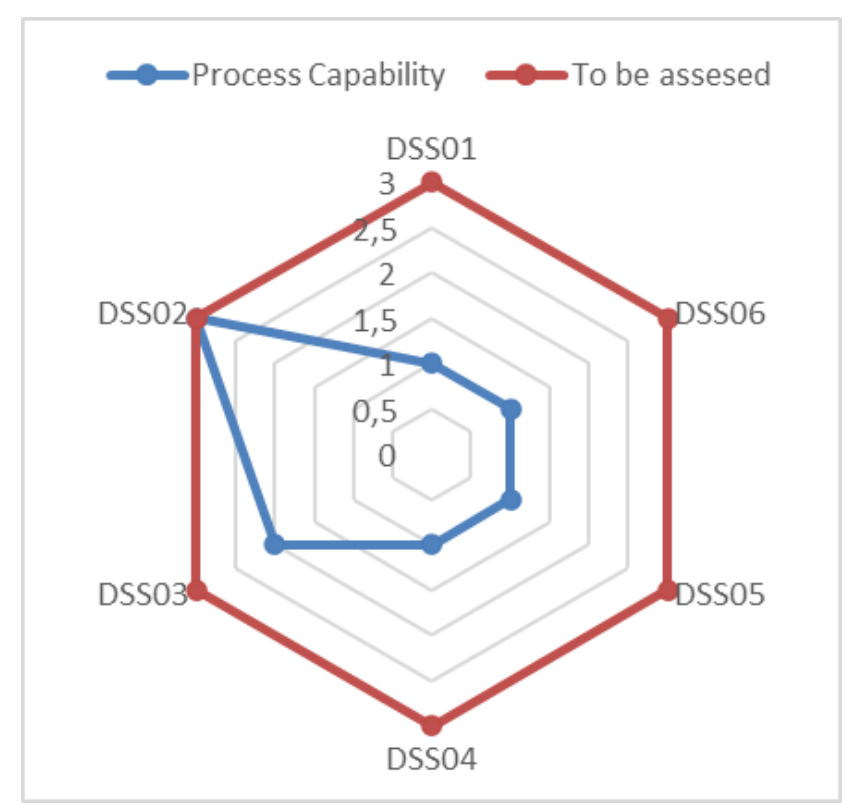

Rekomendasi untuk semua proses sub domain PT. Adicipta Inovasi Teknologi adalah sebagai berikut:

1. Pihak TI PT. Adicipta Inovasi Teknologi perlu membuat SOP yang jelas untuk penggunaan komputer dan internet, untuk meminimalisir resiko dari penggunaan komputer dan internet. (DSS01).

2. Pihak TI perlu melakukan monitoring secara berkala agar tahu bagaimana kondisi operasional TI atau sistem yang ada di PT. Adicipta Inovasi Teknologi. (DSS01).

3. PT. Adicipta Inovasi Teknologi perlu melakukan pelatihan TI berkala untuk karyawankaryawannya, karena selama ini pihak TI PT. Adicipta Inovasi Teknologi tidak bisa berfokus dalam pengembangan sistem operasionalnya dikarenakan mereka lebih sering hanya membantu karyawan lain yang tidak bisa menggunakan TI dengan baik. (DSS01).

4. PT. Adicipta Inovasi Teknologi perlu menambahkan tenaga kerja untuk pihak TI karena selama ini pihak TI tidak bisa melakukan pengembangan sistem untuk operasional PT. Adicipta Inovasi Teknologi secara efektif karena kekurangan tenaga kerja. (DSS01).

5. Pihak TI PT. Adicipta Inovasi Teknologi perlu melakukan dokumentasi saat mengatasi masalah yang ada, hal ini dapat dijadikan acuan masalah apa yang sering dihadapi terhadap komputer atau sistem yang ada sehingga memudahkan perbaikan jika terjadi masalah yang sama di masa mendatang tanpa perlu melakukan identifikasi masalah lagi. Selain itu, dapat juga dijadikan acuan untuk mengetahui device mana yang sering mengalami masalah, sehingga pihak TI dapat melakukan pergantian device daripada memperbaikinya terus-menerus. (DSS03).

6. Pihak TI perlu membuat SOP perawatan sistem yang membantu untuk menjaga keberlangsungan proses bisnis PT. Adicipta Inovasi Teknologi karena secara tidak langsung dengan adanya SOP tersebut, pihak TI perusahaan akan mengetahui kapan harus dilakukannya maintenance dan back-up data dari sistem yang digunakan di PT. Adicipta Inovasi Teknologi. (DSS04). 
7. Pihak TI PT. Adicipta Inovasi Teknologi perlu memastikan antivirus terus di-update secara berkala, selain itu pihak TI juga perlu membuat SOP penggunaan komputer sehingga dapat menyaring device mana saja yang boleh digunakan dalam kegiatan operasional agar keamanan informasi organisasi tetap terjaga. (DSS05).

8. Pihak TI PT. Adicipta Inovasi Teknologi juga perlu memastikan bahwa setiap komputer yang digunakan memiliki password untuk menghindari akses yang tidak diinginkan dari orang yang tidak berkepentingan. (DSS05).

9. Pihak TI perlu membuat SOP untuk perawatan perangkat yang ada di PT. Adicipta Inovasi Teknologi agar perangkat yang ada tidak sering mengalami kerusakan, selain itu dengan adanya SOP perawatan perangkat pihak TI akan memiliki jadwal rutin untuk melakukan perawatan untuk meminimalisir kerusakan perangkat. (DSS05).

10. Pihak TI PT. Adicipta Inovasi Teknologi perlu membuat SOP yang jelas untuk penggunaan komputer dan internet serta melakukan control activities seperti memfilter beberapa situs yang dapat mengganggu performa karyawan sehingga proses bisnis benarbenar terkontrol dengan baik. (DSS06).

\section{KESIMPULAN}

Berdasarkan hasil penelitian yang dilakukan menggunakan COBIT 5 dapat diambil kesimpulan bahwa kinerja tata kelola teknologi informasi yang ada di PT. Adicipta Inovasi Teknologi pada domain DSS (Deliver, Service, Support) menunjukan PT. Adicipta Inovasi Teknologi telah mengimplementasikan semua sub domain DSS. Namun, sampai sekarang masih belum sepenuhnya melakukan dokumentasi dan proses pengelolaan yang baik. Hal ini terlihat dari hasil penilaian proses capability level dari sub domain yang ada menunjukan 4 dari 6 sub domain masih berada pada level 1, Performed Process. Dengan penelitian ini diharapkan PT. Adicipta Inovasi Teknologi dapat meningkatkan kinerja tata kelola teknologi informasi yang ada sehingga dapat memberikan kontribusi meningkatkan efektifitas dan efisiensi penggunaan teknologi informasi untuk mencapai tujuan bisnis PT. Adicipta Inovasi Teknologi. Penggunaan framework COBIT 5 di dalam penelitian ini dapat memperlihatkan posisi dari kinerja tata kelola teknologi informasi sekarang ada di level 1 yaitu perusahaan masih melakukan proses TI berdasarkan kebutuhan yang ada, sehingga diharapkan perusahaan dapat memperbaiki kekurangan yang ada dan menentukan target sejauh mana tata kelola teknologi informasi ingin dikembangkan ke level berikutnya yaitu level 2 (Managed Process). PT. Adicipta Inovasi Teknologi dapat memperbaiki kekurangan dari tata kelola TI nya melalui penerapan rekomendasi yang ditemukan di penelitian ini. Permasalahan seperti tidak ter-up-to-date nya database sistem dapat diatasi dengan pembuatan SOP perawatan sistem. Selain itu, masalah seperti komputer yang rusak dan lambatnya koneksi internet dapat diminimalisir serta diatasi dengan adanya SOP penggunaan komputer saat kerja dan perawatan komputer secara rutin di PT. Adicipta Inovasi Teknologi. Saran untuk penelitian selanjutnya adalah bagaimana melakukan monitoring dan evaluasi terhadap kinerja TI sebagai tindak lanjut terhadap hasil rekomendasi yang telah diberikan 


\section{Referensi}

Achyar A.R., dkk. 2015. Analisis Audit Sistem Informasi Berbasis COBIT 5 Pada Domain Deliver, Service, and Support (DSS) (Studi Kasus: SIM-BL di Unit CDC PT. Telkom Pusat. Tbk). Universitas Telkom.

ISACA. 2014. COBIT 5 Principles, Process Reference Model.

ISACA. 2014. COBIT 5: A Business Framework for Governance \& Management. USA: IT Governance Institute.

ISACA. 2014. COBIT Process Assesment Model (PAM): Using COBIT 5. Rolling Meadows: ISACA.

ISACA. 2015. COBIT 5. United States of America: IT Governance Institute.

Stefan, A., dkk. 2017. Analisis Risiko Teknologi Informasi Menggunakan ISO 31000 pada Program HRMS. Jurnal RESTI Vol. 1 No.3(2017) 250-258.

Wijaya A. F., dkk. 2017. Evaluasi Kinerja Sistem Informasi E-Filing Menggunakan COBIT 5 Pada Kantor Pelayanan Pajak Pratama Kota Salatiga. JUTEI UKDW.

Yanuar F., dkk. 2015. Audit Teknologi Informasi menggunakan Framework COBIT 5 Pada Domain DSS (Delivery, Service, and Support) (Studi Kasus: iGracias Telkom University). Universitas Telkom.

Yap, Pardjo. 2017. Panduan Praktis Manajemen Risiko Perusahaan. Growing Publishing. 